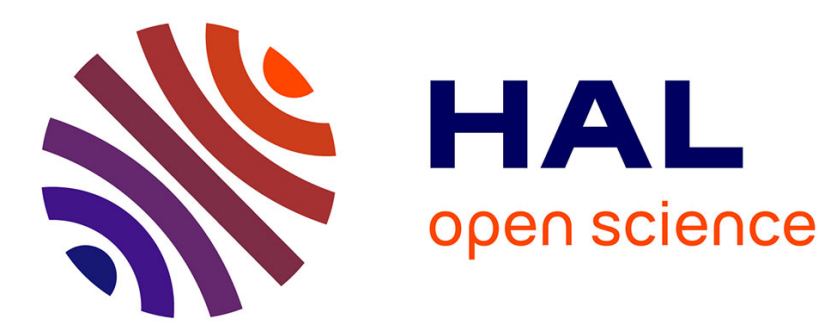

\title{
Sonic cracking of blue-green algae
}

Spiros Kotopoulis, Antje Schommartz, Michiel Postema

\section{To cite this version:}

Spiros Kotopoulis, Antje Schommartz, Michiel Postema. Sonic cracking of blue-green algae. Applied Acoustics, 2009, 70 (10), pp.1306-1312. 10.1016/j.apacoust.2009.02.003 . hal-03193313

\section{HAL Id: hal-03193313 https://hal.science/hal-03193313}

Submitted on 11 Apr 2021

HAL is a multi-disciplinary open access archive for the deposit and dissemination of scientific research documents, whether they are published or not. The documents may come from teaching and research institutions in France or abroad, or from public or private research centers.
L'archive ouverte pluridisciplinaire HAL, est destinée au dépôt et à la diffusion de documents scientifiques de niveau recherche, publiés ou non, émanant des établissements d'enseignement et de recherche français ou étrangers, des laboratoires publics ou privés.

\section{(이) $\$$}

Distributed under a Creative Commons Attribution - NonCommercial - NoDerivatives| 4.0 


\title{
Sonic cracking of blue-green algae
}

\author{
Spiros Kotopoulis, Antje Schommartz, Michiel Postema ${ }^{1}$ \\ Department of Engineering, The University of Hull, Kingston Upon Hull, \\ HU6 7RX, United Kingdom
}

1 Corresponding author. Address: Department of Engineering, The University of Hull, Kingston Upon Hull, HU6 7RX, United Kingdom. Telephone: +44 1482 465670. E-mail: m.postema@hull.ac.uk 


\section{Abstract}

Algae are aquatic organisms classified separately from plants. They are known to cause many hazards to humans and the environment. Algae strands contain nitrogen-producing cells that help them float (heterocysts). It is hypothesized that if the membranes of these cells are disrupted by means of ultrasound, the gas may be released analogous to sonic cracking, causing the strands to sink. This is a desirable ecological effect, because of the resulting suppressed release of toxins into the water.

We subjected small quantities of blue-green algae of the Anabaena sphaerica species to ultrasound of frequencies and pressures in the clinical diagnostic range, and observed the changes in brightness of these solutions over time. Blue green algae were forced to sink at any ultrasonic frequency we studied, supporting our hypothesis that heterocysts release nitrogen under ultrasound insonification in the clinical diagnostic range.

Although the acoustic fields we used to eradicate blue-green algae are perfectly safe in terms of mechanical index, the acoustic pressures surpass the NURC Rules and Procedures by over $35 \mathrm{~dB}$. Therefore, caution should be taken when using these techniques in a surrounding where aquatic or semi-aquatic animals are present.

Key words:

PACS:

\section{$1 \quad 1 \quad$ Introduction}

2 Algae are aquatic, eukaryotic, photosynthetic organisms, ranging in size from 3 single-celled forms to large kelps. Algae are classified separately from plants 4 since they lack true roots, stems, leaves and embryos. Algae are known to

5 cause many health hazards to humans including skin rashes, gastrointestinal, 
6 respiratory [1], allergic reactions, [2] and liver cancer [3]. In addition,

7 blue-green algae may have implications on aquatic and semi-aquatic animals

8 [4]. Eutrophication is the increase in chemical nutrients within the ecosystem,

9 causing blooms of algae and plant life and the subsequent decomposition of

10 blue-green algae by bacteria, an oxygen-consuming process [5]. When billions

11 of such bacterial cells die during a bloom, the water becomes oxygen-depleted,

12 killing off oxygen-dependent organisms [6].

13 The main factors that influence algae growth are temperature and light $[7,8]$.

14 At low temperatures and low light conditions, the algae do not photosynthesise

15 and therefore do not bloom. Algae strands contain nitrogen-producing cells

16 that help them float (heterocysts), as demonstrated in Fig. 1. The heterocysts

17 have a diameter between $5-7 \mu \mathrm{m}$ [9]. It is hypothesized that if the membranes

18 of these cells are disrupted by means of ultrasound, the gas may be released

19 analogous to sonic cracking [10], causing the strands to sink. At the lake bed,

20 illumination is lower, thus reducing algae multiplication. This is a desirable

${ }_{21}$ ecological effect, because of resulting suppressed release of toxins into the

22 water.

${ }_{23}$ There are chemical methods to control certain species of algae, but these

${ }_{24}$ have side-effects such as promotion and growth of other species of algae [11]

25 whilst also affecting aquatic life in fresh water ponds and lakes. Therefore,

26 ultrasonic algae control has been under investigation [12-17]. In [12-17],

27 ultrasonic insonification of different species of algae led to a decrease in algae

28 concentrations in the frequency range $20 \mathrm{kHz}-1.7 \mathrm{MHz}$, which is in contrast

29 with [18], where ultrasound was observed to strengthen the cell membranes

so of red algae. In these studies, the exact acoustic conditions have not been

31 specified other than the frequency and power input. Hence, from the acoustics 
${ }_{41} \quad \mathrm{MI}=\frac{p^{-}}{\sqrt{f}}$,

42

point of view, they are not repeatable. More importantly, the mechanism causing algae eradication or membrane disruption had not been investigated.

Most commercially available equipment works in the lower ultrasonic range [19]. There have been speculations about the physical mechanism behind the algae eradication, specifically about the role of cavitation. In this study, we investigate the effectiveness of ultrasonic insonification in the clinical diagnostic range on Anabaena blue-green algae.

A measure for the safe use of clinical diagnostic ultrasound is the mechanical index (MI) defined by

where $p^{-}$is the maximum value of peak negative pressure anywhere in the ultrasound field, measured in water but reduced by an attenuation factor equal to that which would be produced by a medium having an attenuation coefficient of $0.3 \mathrm{dBcm}^{-1} \mathrm{MHz}^{-1}$, normalised by $1 \mathrm{MPa}$, and $f$ is the centre frequency of the ultrasound normalised by $1 \mathrm{MHz}[20]$. For $\mathrm{MI}<0.3$, the ultrasonic amplitude is considered low. In clinical diagnostics there is a possibility of minor damage to neonatal lung or intestine [20] for $0.3<\mathrm{MI}<0.7$. These are considered moderate acoustic amplitudes. For MI $>0.7$, there is a risk of cavitation if gas cavitation nuclei are present, and there is a theoretical risk of cavitation without the presence of cavitation nuclei [20]. The risk increases 52 with MI values above this threshold [20]. These are considered high acoustic amplitudes. According to the NATO Undersea Research Centre (NURC) Human Diver and Marine Mammal Risk Mitigation Rules and Procedures 5 [21], the maximum acoustic pressure to which mammals can be exposed is $708 \mathrm{~Pa}$ at frequencies up to $250 \mathrm{kHz}$. This corresponds to a mechanical index 
${ }_{57} \mathrm{MI}<0.01 \ll 0.3$. In this paper, we have chosen to work in the lower clinical 58 diagnostic range, taking into account both guidelines. 
To investigate the effect of diagnostic ultrasound on algae eradication, three ultrasound transducers were used. A $200-\mathrm{kHz}$ undamped single element transducer containing a PIC155 Piezo crystal (PI Ceramics, Lederhose, Germany), a PA 188 (Precision Acoustics Ltd, Dorchester, UK) 1-MHz undamped single element transducer, and a 2.2-MHz undamped single element transducer containing a Pz37 Piezo crystal (Ferroperm Piezoceramics A/S, Kvistgård, Denmark). The focal distance of the $2.2-\mathrm{MHz}$ transducer was $73 \mathrm{~mm}$. The design of two transducers is shown in Fig. 2. The transducers were subjected to $16-\mathrm{Vpp}$ square pulses at a $11.8 \mathrm{-kHz}$ pulse repetition rate transmitted by a V1.0 pulser-receiver (Sonemat, Coventry, UK). Low acoustic amplitudes were used in order to comply with $\mathrm{MI}<0.3$ [20]. The acoustic amplitudes were measured in a separate water tank in the acoustic foci of the transducers with a 0.2-mm needle hydrophone (Precision Acoustics Ltd, Dorchester, UK) connected to a TDS 420A four channel digital oscilloscope (Tektronix Inc, Beaverton, USA). The peak-negative acoustic pressures were $40 \mathrm{kPa}$ for the $1-\mathrm{MHz}$ transducer and $68 \mathrm{kPa}$ for the $2.2-\mathrm{MHz}$ transducer, respectively, i.e., $\mathrm{MI} \ll 0.1$.

${ }_{77}$ The algae used were of the Anabaena species. The Anabaena were obtained from an outside lake and cultured in $2 \mathrm{~L}$ of Jaworski's medium [22] at room temperature near a South-facing window in an Erlenmeyer flask for 11 days. The solution was put in a Swirtlock2000 autoclave (Astell Scientific, Kent, UK) at 15-lb pressure for 15 minutes. 
To measure the time-dependent change in brightness of water containing blue-green algae, the culture was split equally into four 250-mL Perspex beakers: one beaker for each transducer and one control beaker. The transducers were inserted separately in each beaker with the acoustic focus within the sample. Each transducer was turned on for 1 hour. The experimental setup is shown in Fig. 3. A digital photograph of the solution was taken every five minutes using an EOS 350D digital photo camera (Canon Inc, Tokyo, Japan). The lighting and exposure settings were controlled and maintained throughout the insonification. Full manual settings were used: ISO 100, exposure time $1 / 50 \mathrm{~s}, \mathrm{~F}$ number 3.50 , focal length $18 \mathrm{~mm}$, no flash, centre weighted metering mode, custom white balance, B4,0 shift. The digital photographs were converted to 8-bit grey scale. On the photographs of the insonified solution and control solution, a square area of $160 \times 160$ pixels was selected, whose average grey scale depth was calculated using MATLAB ${ }^{\circledR}$ (The Mathworks ${ }^{\mathrm{TM}}$, Natick, MA). The change in shade between the first image taken just before insonification and each sequential image after insonification was calculated and graphed for all 18 insonified and control samples. A white sheet was placed behind the beakers to maintain a constant background. The grey scale of the sheet was also measured and used to calibrate the results. In total, 575 measurements were analysed from 122 photographs.

\section{Viability measurements}

Every 10 minutes, a $20-\mu \mathrm{L}$ sample was taken from the insonified solution. Samples were put on a test slide and observed through a CHA microscope 
(Olympus Corporation, Tokyo, Japan) with a $10 \times$ objective lens (Olympus Corporation, Tokyo, Japan). Digital photographs were captured from the microscope's eye piece using an FE-230 digital camera (Olympus Corporation, Tokyo, Japan). Automatic settings were used with Super Macro mode and a -1.0 exposure adjustment. From these digital images, cell deterioration and chlorophyll damage were determined. To investigate the effect of ultrasound on the viability of the cells, fluorescent light was used. When fluorescent light is projected onto chlorophyll, it is absorbed and re-emitted as a red glow. The red glow denotes that the chlorophyll is still active and can photosynthesize, thus the algae strands are still alive. Fluorescent light was used as the method to check the viability of the chlorophyll, since it is a standardized and accepted method in detecting chlorophyll activity in plants $[23,24]$. Fluorescent light was projected onto these samples for no more than 10 seconds in order to capture the digital image. We may assume that there are no disadvantageous effects of the fluorescent light on the algae $[25,26]$. The samples were discarded after being exposed to fluorescent light. Three trials of each frequency were performed. One hundred and thirty-one photographs were taken of the microscopic cell structure.

\section{Post-insonification growth measurements}

To measure the effect of ultrasound on post-insonification blue-green algae growth, twenty-four 1-mL samples were removed from three solutions that had been subjected to 1 hour of insonifcation with 200-kHz, 1.0-MHz and 2.2-MHz ultrasound, respectively, and put into a culture tray with 96 compartments. Twenty-four control samples were taken. The culture tray was left in sunlight for 30 days. The grey scale depth was measured for each compartment. 


\section{Results and Discussion}

Figure 4 shows the microscopic effect of ultrasound on floating bodies in the algae solution. From 0 minutes to 60 minutes of insonification, no change was seen in the physical structure of the algae for the whole frequency range. Illuminating the algae with fluorescent light showed that the ultrasound had no effect on the chlorophyll activity for the whole frequency range. The active chlorophyll shows that the algae strands are still alive and able to photosynthesise after 60 minutes insonification. This indicates that the ultrasound transmitted does not affect the chlorophyll-containing cells themselves, which is desirable since no toxins are released this way.

However, Fig. 5 shows that at all frequencies, for the floating bodies, the insonified samples showed greater brightness than the control samples. For the sunken bodies, all insonified samples showed reduced clarity as compared to the control samples. Thus, the ultrasound has caused the algae to sink. For example, after 60 minutes, the beakers subjected to $200-\mathrm{kHz}$ insonification were $92 \pm 12 \%$ brighter than the control samples, contrasted by the beaker bottoms, which were $53 \pm 27 \%$ darker than the control samples.

Clearly, the algae that were floating in the beaker dropped to the bottom at a faster rate than the control sample. This has been attributed to the disruption of the floating bodies by the ultrasound. This is supported by Fig. 6, which shows that the sunken bodies still have active chlorophyll but contain very few heterocysts.

Figure 7 shows the viability of the culture 30 days after insonification in terms of sample brightness. At $200 \mathrm{kHz}, 1.0 \mathrm{MHz}$, and $2.2 \mathrm{MHz}$, the samples 
were $39 \pm 14 \%, 45 \pm 17 \%$, and $46 \pm 17 \%$ brighter than the control samples, respectively. All samples were significantly brighter than the control samples, even at the lower boundaries of the standard deviation. Thus, these results support the hypothesis that the algae that have sunk are less capable of multiplying. Hence, insonification may prevent algae bloom.

Our results can be interpreted as follows. When a heterocyst is subjected to an ultrasound pulse, the bubble encapsulated by it expands, in our frequency range [27] during the rarefaction phase of the ultrasound. If the acoustic amplitude is sufficiently high, the encapsulating membrane cannot withhold the bubble from further expanding, resulting in its rupture. This phenomenon is similar to the sonic cracking of micrometer-sized membrane-encapsulated bubbles observed in [10]. Sonic cracking exclusively occurs during the expansion phase of a bubble [28].

The resonance frequency $f_{0}$ of a an encapsultaed microbubble is given by [29]:

$$
f_{0}=\frac{1}{2 \pi} \sqrt{\left(\frac{3 \Gamma}{R_{0}^{2} \rho}\right)\left(p_{0}+\frac{2 \sigma}{R_{0}}+\frac{2 \chi}{R_{0}}\right)-\left(\frac{2 \sigma+6 \chi}{R_{0}^{3} \rho}\right)}
$$

where $p_{0}$ is the ambient pressure, $R_{0}$ is the bubble radius, $\Gamma$ is the polytropic exponent of the gas, $\rho$ is the liquid density, $\sigma$ is the surface tension, and $\chi$ is the elasticity of the encapsulation [29]. Using $p_{0}=1.013 \times 10^{5} \mathrm{~Pa}, R_{0}=3 \mu \mathrm{m}$, $\Gamma=1.4, \rho$ is $998 \mathrm{kgm}^{-3}, \sigma=0.072 \mathrm{Nm}^{-1}$, and assuming that the membrane elasticity is similar to that of a lipid encpsulation, $\chi=0.044 \mathrm{Nm}^{-1}$ [30], we can estimate $f_{0} \approx 1 \mathrm{MHz}$ for Anabaena heterocysts used in our experiments. Since the greatest change in clarity was seen at this particular frequency, we can safely state that ultrasound insonification close to heterocyst resonance frequency leads to a more effective eradication. 
179 The quick decrease in live algae is similar to that in previous studies [12-17].

180 We assume that the correlation between (high)frequency and algae eradication 181 in these studies is related to the ultrasound proximity to heterocyst resonance 182 as well.

183 According to the NURC Rules and Procedures [21], the maximum acoustic 184 pressure to which mammals can be exposed is $708 \mathrm{~Pa}$ at frequencies up to $185250 \mathrm{kHz}$. The transducers used had acoustic pressures of $40 \mathrm{kPa}$ and $68 \mathrm{kPa}$ at 186 driving frequencies $1.0 \mathrm{MHz}$ and 2.2 MHz, respectively. These pressures surpass 187 the NURC Rules and Procedures by over $35 \mathrm{~dB}$. 


\section{Conclusion}

189 At any ultrasonic frequency we studied, blue-green algae were forced to 190 sink. This supports our hypothesis that heterocysts release nitrogen under 191 ultrasound insonification in the clinical diagnostic range. As supported by 192 previous studies, under identical pulse length and pulse repetition, eradication 193 is most effective close to heterocyst resonance, at a driving frequency of 194 roughly $1 \mathrm{MHz}$.

195 Although the acoustic fields we used to eradicate blue-green algae are safe in 196 terms of mechanical index, the acoustic pressures surpass the NURC Rules 197 and Procedures by over $35 \mathrm{~dB}$. Therefore, caution should be taken when using 198 these techniques in a surrounding where aquatic or semi-aquatic animals are 199 present.

\section{Acknowledgments}

201 This work has been supported by EPSRC grant EP/F037025/1 and the HERI ${ }_{202}$ Research Pump Priming Fund. We would like to thank John Adams, The 203 University of Hull, for support with the experimental setup. 


\section{References}

[1] Turner PC, Gammie AJ, Hollinrake K, Codd GA. Pneumonia associated with contact with cyanobacteria. Br Med J 1990;300(6737):1440-1441.

[2] Stewart I, Schluter PJ, Shaw GR. Cyanobacterial lipopolysaccharides and human health: a review. Environ Health 2006;5(7):1-23.

[3] Fleming LE, Rivero C, Burns J, Williams C, Bean JA, Shea KA, Stinn J. Blue green algal (cyanobacterial) toxins, surface drinking water, and liver cancer in Florida. Harmful Algae 2002;1(2):157-168.

[4] Bury N. The toxicity of cyanobacteria (blue-green algae) to freshwater fish. Comp Biochem Physiol A 2007;146(4):S92-S93.

[5] San Diego-McGlone ML, Azanza RV, Villanoy CL, Jacinto GS. Eutrophic waters, algal bloom and fish kill in fish farming areas in Bolinao, Pangasinan, Philippines. Marine Poll Bull 2008;57(6-12):295-301.

[6] Hylland K, Sköld M, Gunnarsson JS, Skei J. Interactions between eutrophication and contaminants. IV. Effects on sediment-dwelling organisms. Marine Poll Bull 1996;33(1-6):90-99.

[7] Dauta A, Devaux J, Piquemal F, Bouminch L. Growth rate of four freshwater algae in relation to light and temperature. Hydrobiologia 1990;207(1):221-226.

[8] Allen MB, Arnon DI. Studies on nitrogen-fixing blue-green algae. I. Growth and nitrogen fixation by anabaena cylindrica lemm. Plant Physiol 1955; $30(4): 366-372$.

[9] Lang N, Krupp J, Koller A. Morphological and ultrastructural changes in vegetative cells and heterocysts of anabaena variabilis grown with fructose. J Bacteriology 1987;169(2):920-923. 
[10] Postema M, Bouakaz A, Versluis M, de Jong N. Ultrasound-induced gas release from contrast agent microbubbles. IEEE Trans Ultrason Ferroelect Freq Contr 2005;52(6):1035-1041.

[11] Ferrier MD, Butler Sr BR, Terlizzi DE, Lacouture RV. The effects of barley straw (hordeum vulgare) on the growth of freshwater algae. Biores Tech 2005; 96(16):1788-1795.

[12] Zhang G, Zhang P, Wang B, Liu H. Ultrasonic frequency effects on the removal of Microcystis aeruginosa. Ultrason Sonochem 2006;13(5):446-450.

[13] Ma B, Chen Y, Hao H, Wu M, Wang B, Lv H, Zhang G. Influence of ultrasonic field on microcystins produced by bloom-forming algae. Colloids Surf B 2005; 41(2-3):197-201.

[14] Zhang G, Zhang P, Liu H, Wang B. Ultrasonic damages on cyanobacterial photosynthesis. Ultrason Sonochem 2006;13(6):501-505.

[15] Hao H, Wu M, Chen Y, Tang J, Wu Q. Cavitation mechanism in cyanobacterial growth inhibition by ultrasonic irradiation. Colloids Surf B 2004; $33(3-4): 151-156$.

[16] Tang J, Wu Q, Hao H, Chen Y, Wu M. Growth inhibition of the cyanobacterium spirulina (arthrospira) platensis by $1.7 \mathrm{mhz}$ ultrasonic irradiation. J Appl Phycol 2003;15(1):37-43.

[17] Zhang G, Zhang P, Fan M. Ultrasound-enhanced coagulation for microcystis aeruginosa removal. Ultrason Sonochem 2009;16(3):334-338.

[18] Chen B, Huang J, Wang J, Huang L. Ultrasound effects on the antioxidative defense systems of porphyridium cruentum. Colloids Surf B 2008;61(1):88-92.

[19] Postema M. Onderzoek naar de veilige toepassing van ultrageluid gebruikt om blauwalg te bestrijden. Technical report, Memo. The University of Hull 2007. 
[20] British Medical Ultrasound Society. Guidelines for the safe use of diagnostic ultrasound equipment 2000 .

[21] Undersea Research Centre N. Human diver and marine mammal risk mitigation rules and procedures. Technical report, NURC-SP-2006-008 2006.

[22] Culture Collection of Algae and Protozoa. Media Recipes, volume EG:JM 2007.

[23] Ventrella A, Catucci L, Agostiano A. Effect of aggregation state, temperature and phospholipids on photobleaching of photosynthetic pigments in spinach photosystem ii core complexes. Bioelectrochemistry 2008;73(1):43-48.

[24] Mateos-Naranjo E, Redondo-Gómez S, Cambrollé J, Enrique Figueroa M. Growth and photosynthetic responses to copper stress of an invasive cordgrass, spartina densiflora. Marine Environm Res 2008;66(4):459-465.

[25] Ohl C, Wolfrum B. Detachment and sonoporation of adherent hela-cells by shock wave-induced cavitation. BBA-General Subjects 2003;1624(1-3):131-138.

[26] Kooiman K, Böhmer M, Emmer M, Vos H, Chlon C, Foppen-Harteveld M, Versluis M, de Jong N, van Wamel A. Ultrasound-triggered local release of lipophilic drugs from a novel polymeric ultrasound contrast agent. J Control Release 2008;132(3):e41-e42.

[27] Postema M, Schmitz G. Ultrasonic bubble in medicine: Influence of the shell. Ultrason Sonochem 2007;14(4):438-444.

[28] Postema M, van Wamel A, Lancée CT, de Jong N. Ultrasound-induced encapsulated microbubble phenomena. Ultrasound Med Biol 2004; $30(6): 827-840$.

[29] Postema M, Schmitz G. Bubble dynamics involved in ultrasonic imaging. Expert Rev Mol Diagn 2006;6(3):493-502.

[30] Gorce JM, Arditi M, Schneider M. Influence of bubble size distribution on 
278 the echogenicity of ultrasound contrast agents: A study of SonoVue ${ }^{\mathrm{TM}}$. Invest 279 Radiol 2000;35(11):661-671. 


\section{List of Figures}

1 Nitrogen-fixating body in Anabaena sphaerica algae. Under fluorescent light the body does not illuminate red, proving there is no chlorophyll in the body. Each frame corresponds to $565 \times 565 \mu \mathrm{m}^{2}$.

2 (a) Undamped 2.2-MHz ultrasound transducer with $d=1$ " diameter and $r_{\mathrm{a}}=35 \mathrm{~mm}$ acoustic lens. (b) Undamped 200-kHz ultrasound transducer with modification layer $h_{\mathrm{PG}}=$ $10 \mathrm{~mm}$.

3 Experimental setup: (a) white paper sheet; (b) control sample; (c) clamp stand; (d) transducer; (e) insonified sample; (f) pulser-receiver. Areas A1 - B2 represent brightness measurement areas, $\mathrm{C} 1$ represents the calibration area.

4 Microscopic image sequence showing the effect of $200 \mathrm{kHz}-$ $2.5 \mathrm{MHz}$ ultrasound on the floating bodies of algae. Each frame corresponds to $565 \times 565 \mu \mathrm{m}^{2}$.

5 Water brightness as a function of ultrasonic exposure time for samples containing floating algae or sunken algae.

6 Microscopic image sequence of sunken algae Each frame corresponds to $565 \times 565 \mu \mathrm{m}^{2}$. 


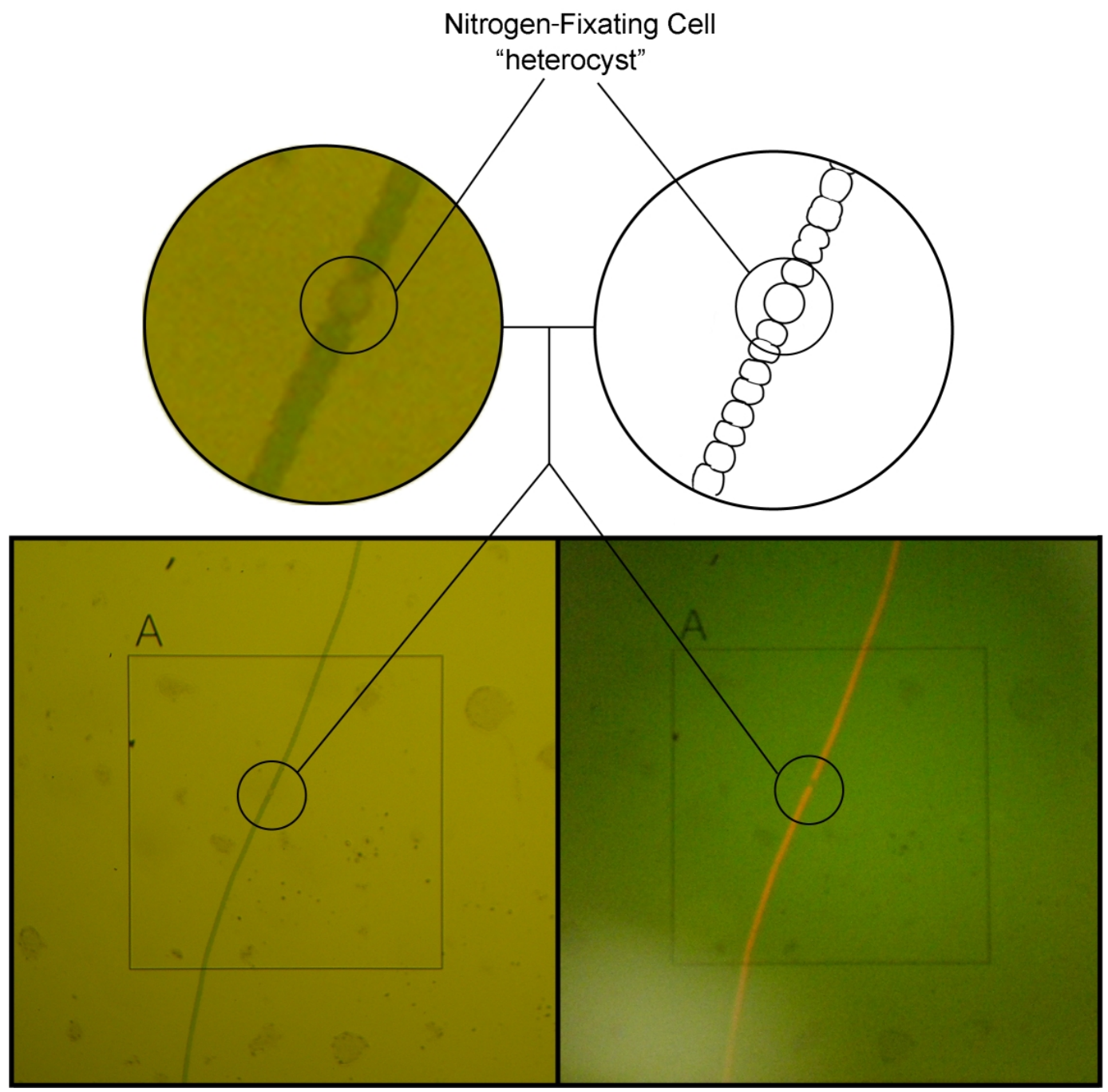

Fig. 1. Nitrogen-fixating body in Anabaena sphaerica algae. Under fluorescent light the body does not illuminate red, proving there is no chlorophyll in the body. Each frame corresponds to $565 \times 565 \mu \mathrm{m}^{2}$. 


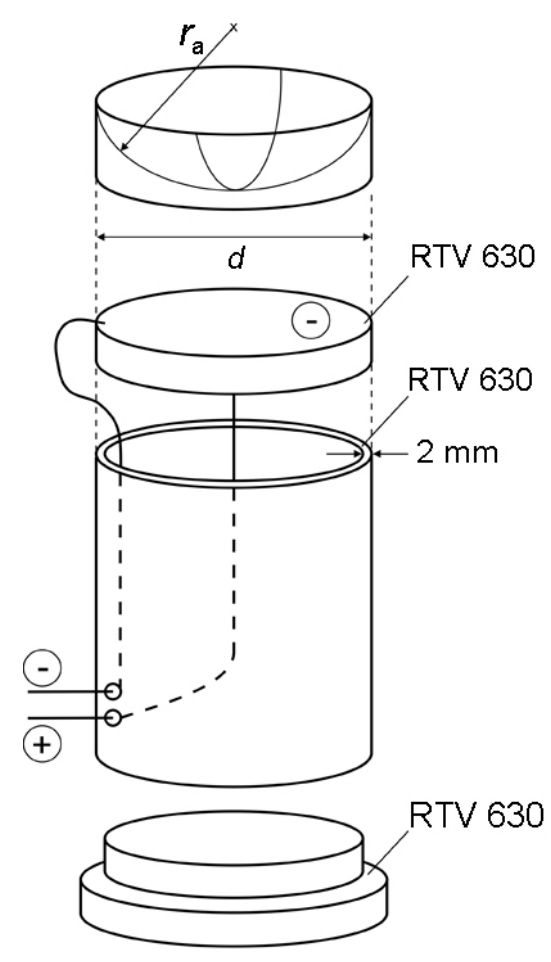

(a)

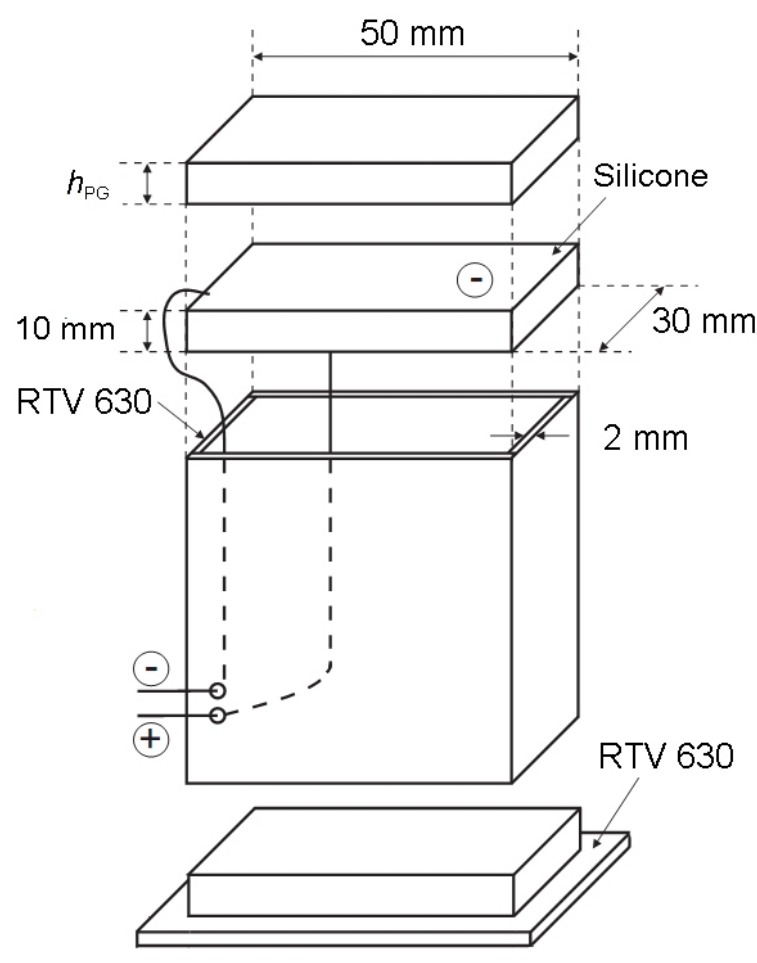

(b)

Fig. 2. (a) Undamped 2.2-MHz ultrasound transducer with $d=1$ " diameter and $r_{\mathrm{a}}=35 \mathrm{~mm}$ acoustic lens. (b) Undamped $200-\mathrm{kHz}$ ultrasound transducer with modification layer $h_{\mathrm{PG}}=10 \mathrm{~mm}$. 


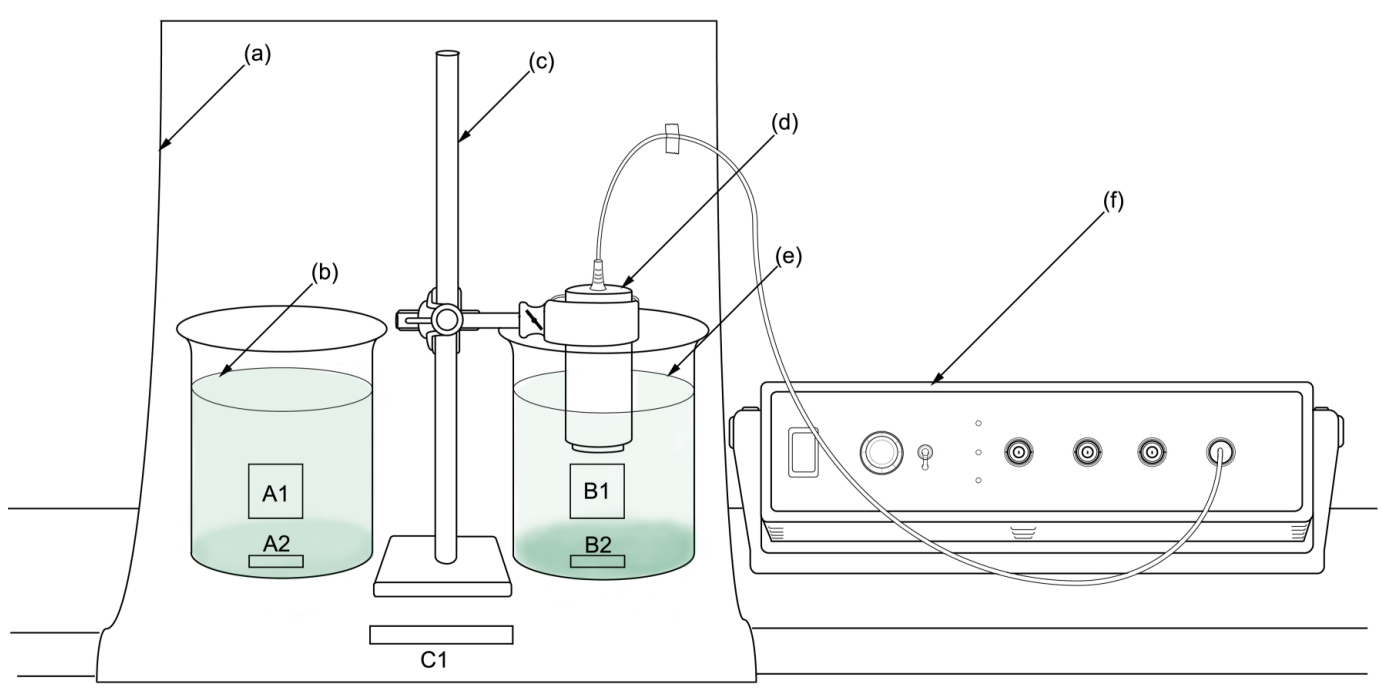

Fig. 3. Experimental setup: (a) white paper sheet; (b) control sample; (c) clamp stand; (d) transducer; (e) insonified sample; (f) pulser-receiver. Areas A1 - B2 represent brightness measurement areas, $\mathrm{C} 1$ represents the calibration area. 
Tungsten Light

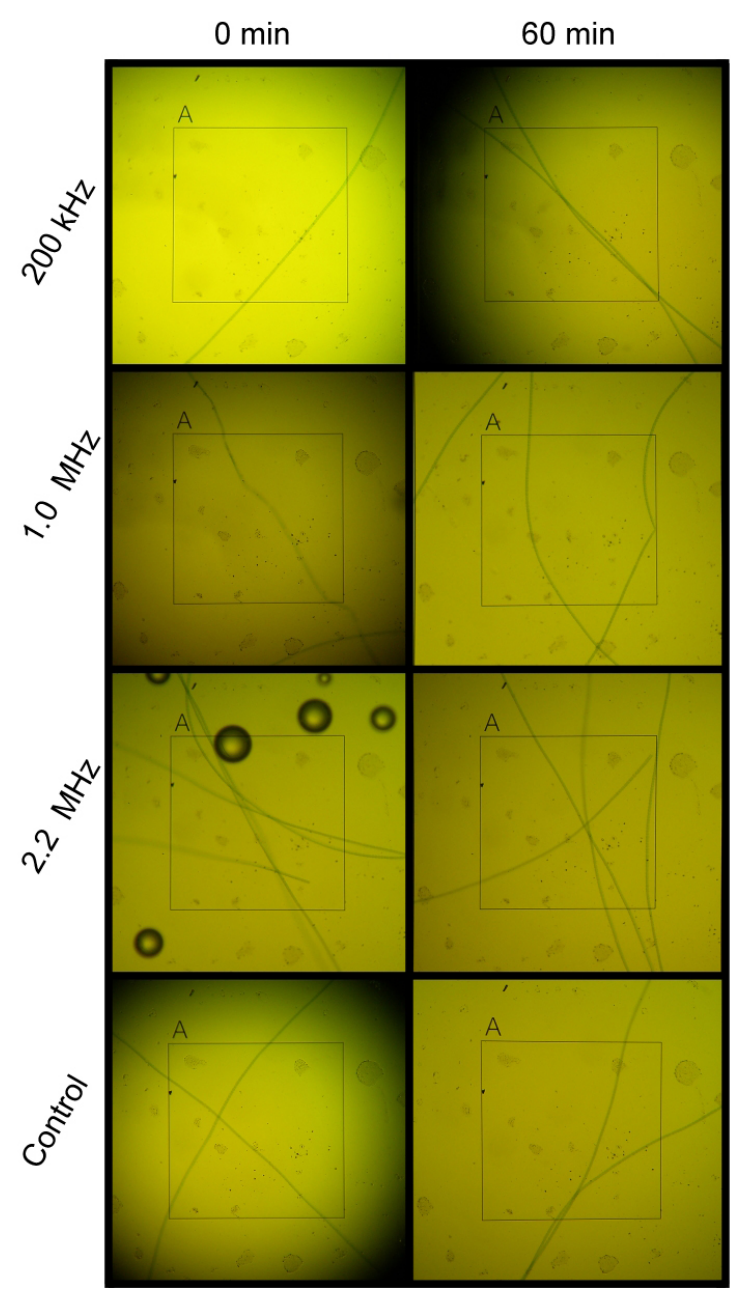

Fluorescent Light

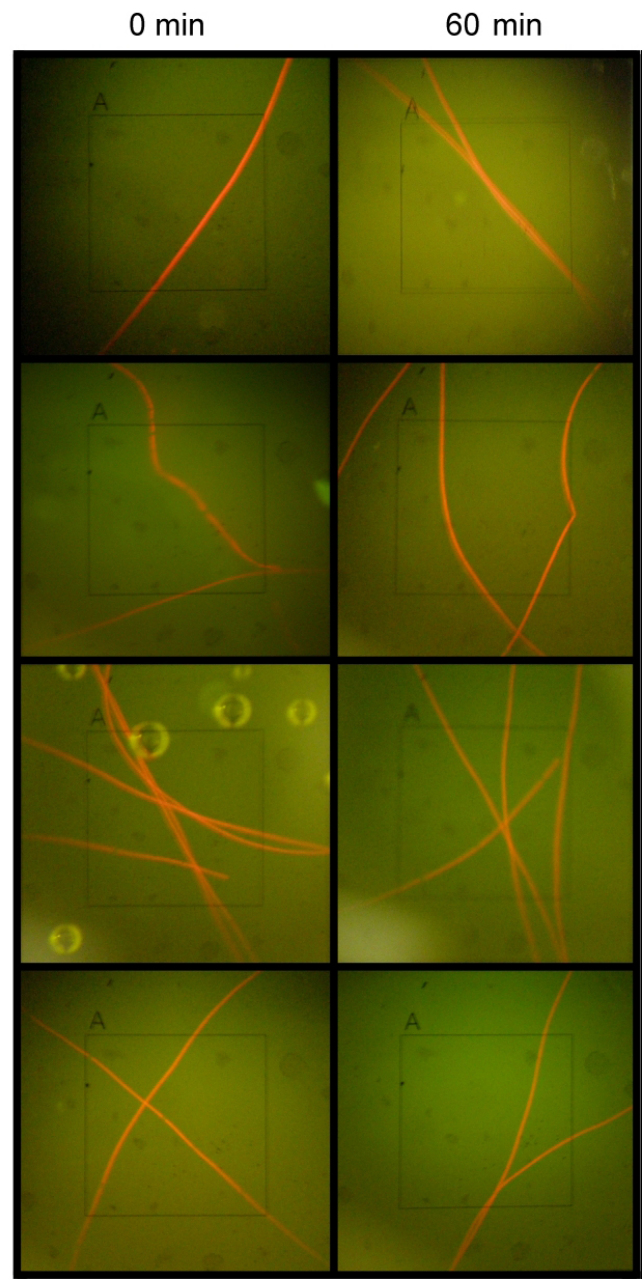

Fig. 4. Microscopic image sequence showing the effect of $200 \mathrm{kHz}-2.5 \mathrm{MHz}$ ultrasound on the floating bodies of algae. Each frame corresponds to $565 \times 565$ $\mu \mathrm{m}^{2}$. 


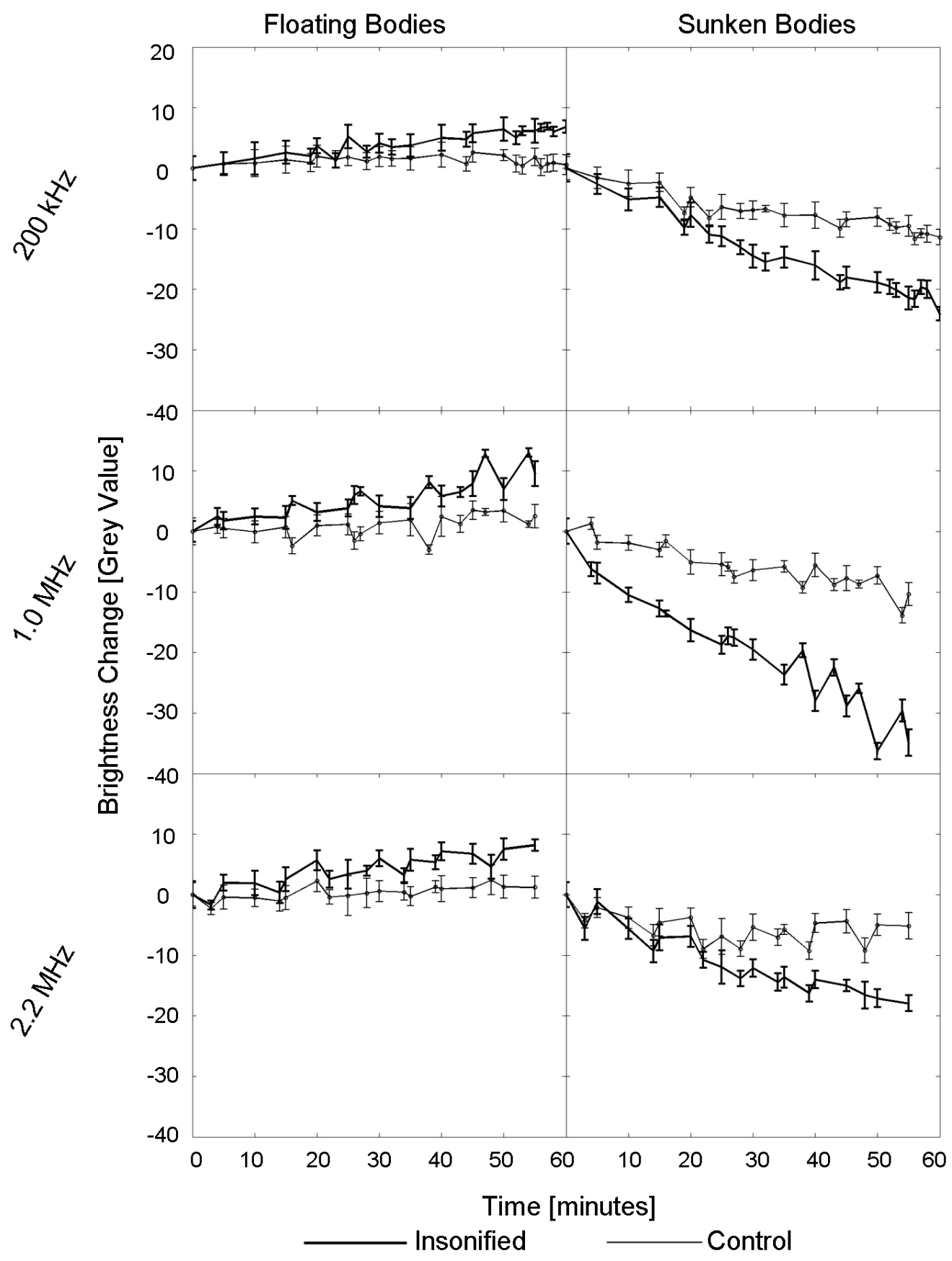

Fig. 5. Water brightness as a function of ultrasonic exposure time for samples containing floating algae or sunken algae. 
Tungsten Light

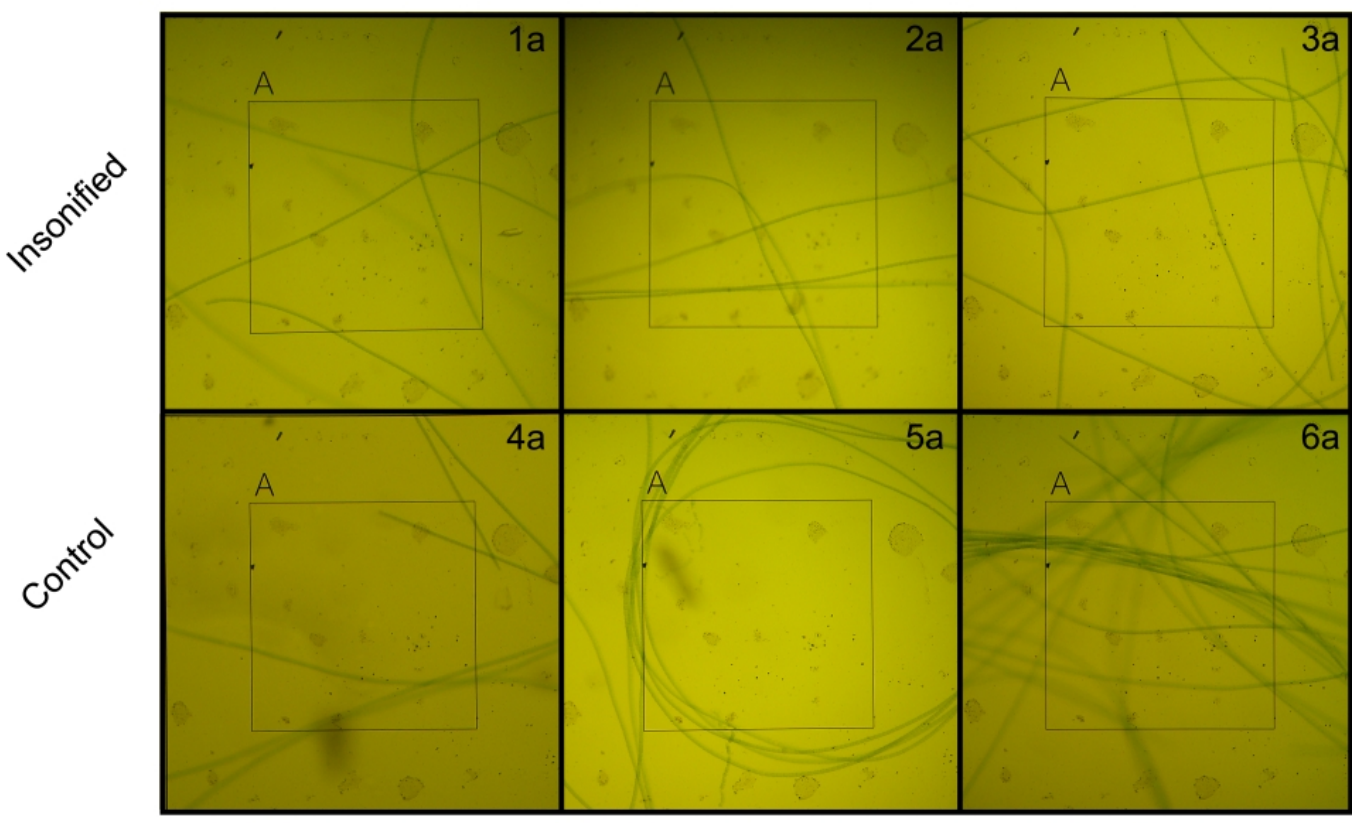

Fluorescent Light

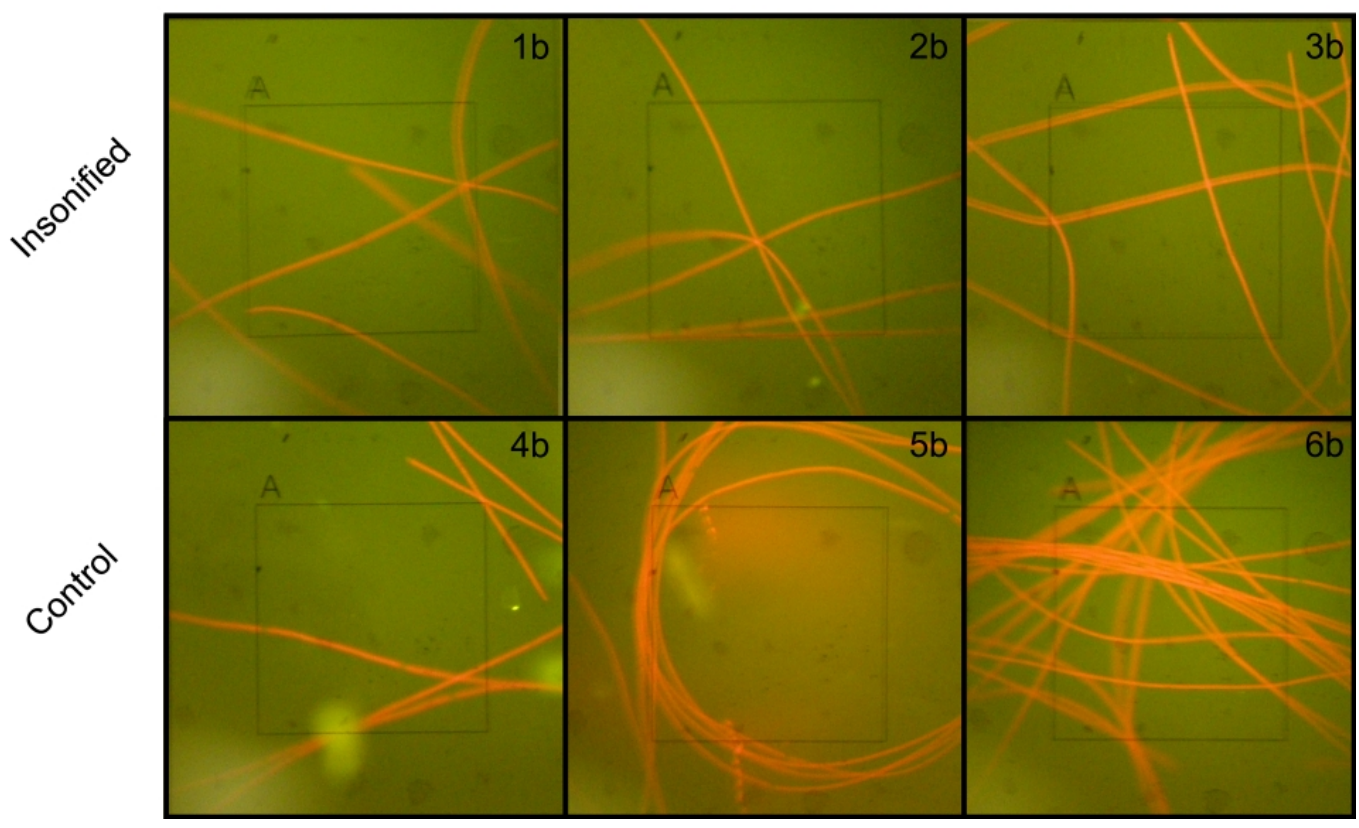

Fig. 6. Microscopic image sequence of sunken algae Each frame corresponds to 565 $\times 565 \mu \mathrm{m}^{2}$. 


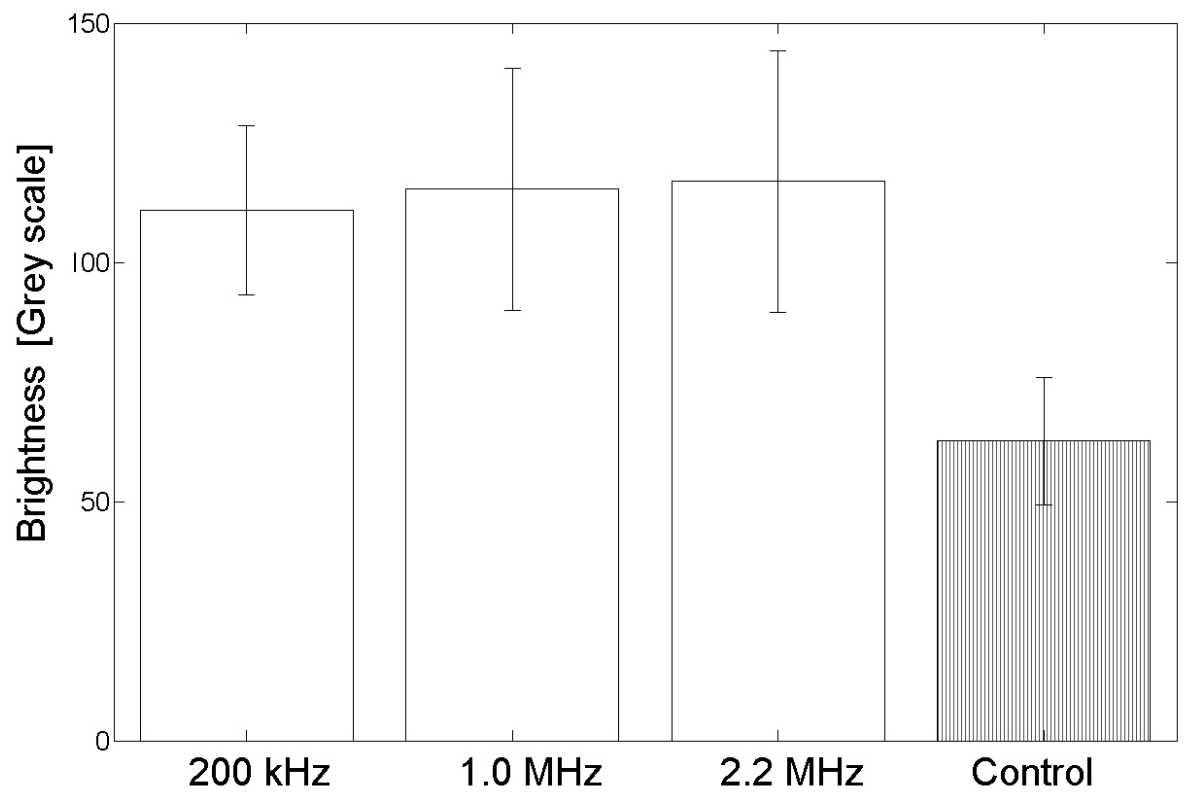

Fig. 7. Water clarity 30 days after insonification. 